RECORDS OF PHARMACEUTICAL
AND BIOMEDICAL SCIENCES

\title{
Antimicrobial Activity of the Crude Ethanolic Extract of Carrichtera annua DC. Collected from Sinai, Egypt
}

\author{
Enas E. Eltamany ${ }^{a}$, Haidy A. Ahmed ${ }^{b}$, Safwat A. Ahmed ${ }^{a^{*}}$, Jihan M. Badr ${ }^{a}$ \\ ${ }^{a}$ Department of Pharmacognosy, Faculty of Pharmacy, Suez Canal University, Ismailia 41522, Egypt; \\ ${ }^{b}$ Ismailia Health Affairs Directorate, Ismailia 41525, Egypt.
}

Received on: 05-2-2021

Revised on: 26-2-2021

Accepted on: 2-3-2021

Correspondence Author:

Tel: +201273292644

E-mail address:

safwat_aa@yahoo.com

\begin{abstract}
Carrichtera annua a plant belonging to family Brassicaceae was evaluated for the antimicrobial activity against a number of microorganisms. The powdered plant was extracted with ethanol. The concentrated ethanol extract was tested against a number of fungi, gram positive and gram-negative bacteria. The results revealed that the extract showed a significant and promising activity towards Aspergillus fumigatus, Proteus vulgaris, Enterococcus faecalis and Staphylococcus aureus with inhibition zones equal 17, 15, 13 and $11 \mathrm{~mm}$. respectively. Additionally, the minimum inhibitory concentration (MIC) was determined and illustrated that, the most susceptible organisms to C. аnnua were Aspergillus fumigatus and Proteus vulgaris with $\mathrm{MIC}$ of $2.5 \mathrm{mg} / \mathrm{mL}$ and 5 $\mathrm{mg} / \mathrm{mL}$ respectively. Therefore, $C$. аппиа could be considered as a promising source for effective antimicrobial agent.
\end{abstract}

Keywords: Carrichtera annua; Brassicaceae; antimicrobial activity.

\section{Introduction}

The rapid development of microbial resistance against chemotherapeutic agents (mostly antibiotics) has emerged as one of the principal public health problems of the 21 st century that threatens the effective prevention and treatment of an ever-increasing range of infections caused by microorganisms (Prestinaci et al., 2015; Atef et al., 2019). The reduced efficacy and increasing toxicity of synthetic drugs further aggravate this problem. As a consequence, scientists are urgently seeking for more effective, safe, cheap, and available antimicrobial agents from various medicinal plants (Dzotam and Kuete, 2017; Atef et al., 2019) since, they have the ability to produce an arsenal of metabolites with unique and diverse bioactivities.

Brassicaceae is a family comprises about 350 genera including about 3500 species (Sasaki et al.,
2002). Consumption of Brassicaceae vegetables regularly is considered as a good supply of bioactive compounds and nutrients in the everyday diet (Shankar et al., 2019; Kaushik et al., 2000). All over the world, Brassicaceae vegetables are consumed as a valuable food. It is considered to as an excellent source of vitamins, amino acids, minerals, carbohydrates (Kaushik et al., 2000). Additionally, other phytochemicals such as flavonoids (De Pascale et al., 2007), phenolics (Cartea et al., 2010; Jahangir et al., 2009), alkaloids (Ramirez et al., 2020) and glucosinolates (Vallejo et al., 2014) were also reported. These phytochemicals contribute to a number of activities including antioxidant, anti-inflammatory (Ateya et al., 2016), anticancer (Hanahan et al., 2000), cardiovascular protective (Cartea et al., 2010), antipyretic and anti-vomiting (khan et al., 2013; Gulshan et al., 2012). Moreover, antimicrobial 
Eltamany et al.

activity was reported to a number of plants belonging to family Brassicaceae (Prasad, 2014). In the present study, Carrichtera annua a Brassicaceae plant was collected from Sinai, Egypt. The ethanolic extract of the plant was evaluated for its antimicrobial activity against selected microorganisms.

\section{Results and discussion:}

C. апnиa extract was prepared as mentioned in our previous study (Eltamany et al., 2020). Then the antimicrobial potential of the obtained extract was evaluated in vitro by qualitative method using agar well diffusion method described in El -Gaby et al., 2018; and quantitative method (minimum inhibitory concentration) (MIC). The antibacterial assay was conducted against Bacillus subtilis NRRL B-543, Bacillus cereus RCMB 027 (1), Staphylococcus aureus ATCC 25923, Methicillin-Resistant Staphylococcus aureus (MRSA) and Enterococcus faecalis ATCC 29212 as examples of Gram-positive bacteria. While, Salmonella typhimurium ATCC 14028 Escherichia coli ATCC 25922, Klebsiella pneumonia ATCC 13883, Proteus vulgaris ATCC 13315 and Pseudomonas aeruginosa ATCC 27853 were employed as examples of Gram-negative bacteria, using Gentamycin antibiotic as a reference broad spectrum antibacterial agent. In addition, the
Rec. Pharm. Biomed. Sci. 5 (2), 60-63, 2021

antifungal activity of $C$. аппиа was assessed against a representative panel of fungal strains i.e., Aspergillus fumigatus (filamentous fungi), Candida albicans (yeast) and Trichophyton rubrum RCMB 065001 (Dermatophytes), using Ketoconazol as a reference antifungal medication. The extract was evaluated for the activity at a concentration of $20 \mathrm{mg} / \mathrm{mL}$ and inhibition zone diameter in $\mathrm{mm}$ was applied as a criterion for the antimicrobial activity. The observations are displayed in (Table 1). According to the obtained results, $C$. annua extract displayed variable in vitro antimicrobial effects. Interestingly, the tested extract showed remarkable antifungal potential against the Aspergillus fumigatus with a zone of inhibition of $17 \mathrm{~mm}$ while it was inactive against the other tested fungi. Moreover, the extract exhibited a promising antibacterial effect on Enterococcus faecalis, Staphylococcus aureus and Proteus vulgaris which was the highly susceptible organism to $C$. annua extract with a zone of inhibition of $15 \mathrm{~mm}$ compare to Gentamycin the reference antibiotic used in this study. Besides, C. annua showed a weak activity against Bacillus subtilis and Klebsiella pneumonia. In contrast the tested extract was inactive as an antibacterial agent on Bacillus cereus, (MRSA), Salmonella typhimurium, Escherichia coli and Pseudomonas aeruginosa.

Table 1. Antimicrobial activity of $C$. annua ethanolic extract against an array of pathogens

\begin{tabular}{|c|c|c|c|}
\hline \multirow[t]{2}{*}{ Tested organisms } & \multicolumn{3}{|c|}{ Zone of inhibition in (mm) } \\
\hline & $\begin{array}{c}\text { C. annua extract } \\
(20 \mathrm{mg} / \mathrm{mL})\end{array}$ & $\begin{array}{l}\text { Ketoconazole } \\
(1 \mathrm{mg} / \mathrm{ml})\end{array}$ & $\begin{array}{l}\text { Gentamycin } \\
(100 \mu \mathrm{g} / \mathrm{mL})\end{array}$ \\
\hline Aspergillus fumigatus RCMB 002008 & 17 & 20 & NT \\
\hline Candida albicans ATCC 10231 & NA & 20 & NT \\
\hline Trichophyton rubrum RCMB 065001 & NA & 13 & NT \\
\hline Staphylococcus aureus ATCC 25923 & 11 & NT & 24 \\
\hline Bacillus subtilis NRRL B-543 & 8 & NT & 26 \\
\hline Bacillus cereus RCMB 027 (1) & NA & NT & 25 \\
\hline Methicillin-Resistant Staphylococcus aureus (MRSA) & NA & NT & 15 \\
\hline Enterococcus faecalis ATCC 29212 & 13 & NT & 26 \\
\hline Salmonella typhimurium ATCC 14028 & NA & NT & 18 \\
\hline Escherichia coli ATCC 25922 & NA & NT & 30 \\
\hline Klebsiella pneumonia АТСC 13883 & 8 & NT & 21 \\
\hline Proteus vulgaris ATCC 13315 & 15 & NT & 25 \\
\hline Pseudomonas aeruginosa ATCC 27853 & NA & NT & 27 \\
\hline
\end{tabular}

The test was done using the diffusion agar technique, well diameter: $6.0 \mathrm{~mm}, 100 \mu \mathrm{l}$ was tested, Positive control for fungi: Ketoconazole ( $1 \mathrm{mg} / \mathrm{ml})$, Positive control for bacteria: Gentamycin $(100 \mu \mathrm{g} / \mathrm{mL}) * \mathrm{NA}$ : No activity, NT: Not tested. 


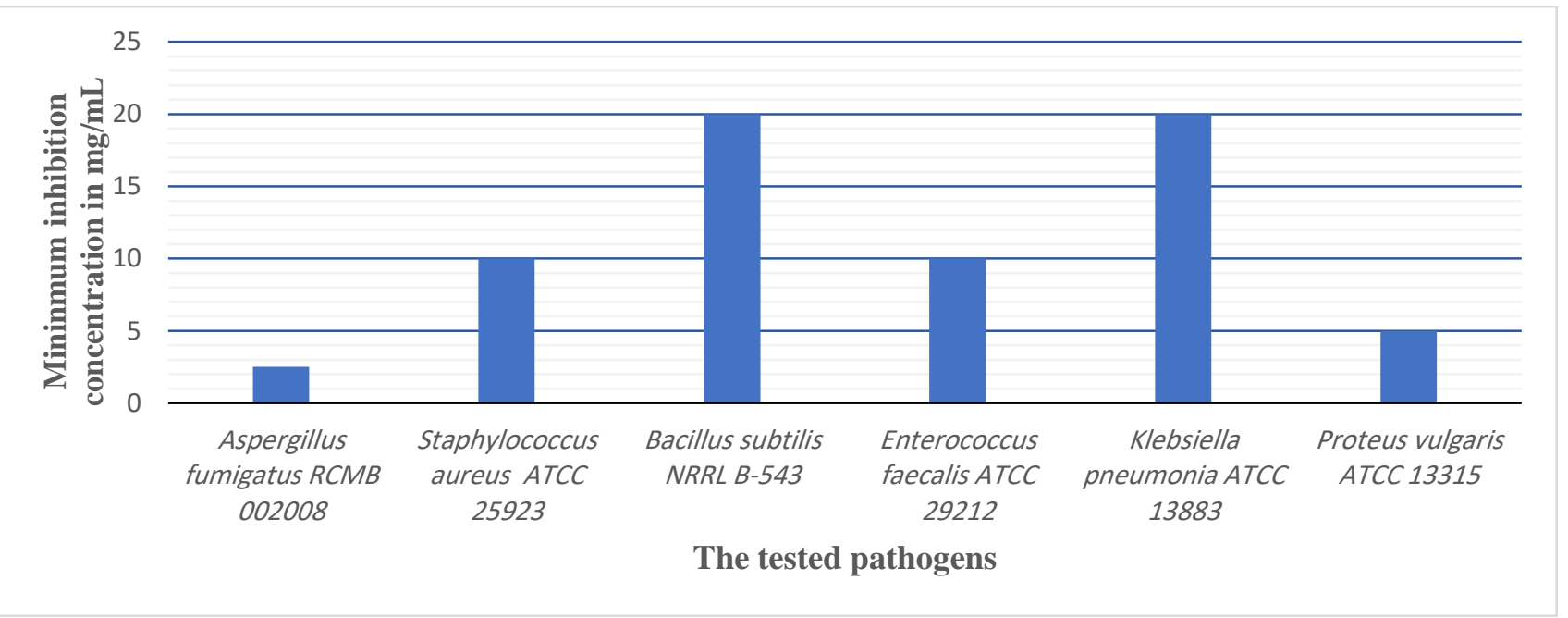

Figure 1. Minimum inhibition concentration (MIC) of C. annua against selected pathogens

The MIC of $C$. annua extract against the most sensitive organisms was determined using modified agar well diffusion method. The obtained results as shown in Figure 1 were consistent with those obtained from the previous antibacterial test in the present study. C. аnnua had the highest activity on Aspergillus fumigatus (MIC $2.5 \mathrm{mg} / \mathrm{mL}$ ) followed by Proteus vulgaris (MIC $5 \mathrm{mg} / \mathrm{mL}$ ) whereas the extract possessed the lowest activity on both Bacillus subtilis and Klebsiella pneumonia (MIC 20 $\mathrm{mg} / \mathrm{mL}$ ).

\section{Conclusion}

In the present study, we have evaluated the antimicrobial activity of $C$. аnnua ethanolic extract. our observations revealed that $C$. annua could be a promising lead for the developments of effective therapeutic agents especially against Aspergillus fumigatus and Proteus vulgaris. Therefore, a future bioassay guided phytochemical study is need to isolate the bioactive compound then assess their activities as effective antibacterial and antifungal agents.

\section{References}

The Atef, N., Shanab, S., Negm, S., Abbas, Y. 2019. Evaluation of antimicrobial activity of some plant extracts against antibiotic susceptible and resistant bacterial strains causing wound infection. Bulletin of the National Research Centre, 43, 144.

Ateya, A., Al-Gendy, A., Kotob, S., Hafez, A. 2016. Chemical constituents, antioxidant, antimicrobial and antiinflammatory activities of Erysimum corinthium boiss. (Brassicaceae). International Journal of Pharmacognosy and Phytochemistry Research, 8, 1601-1609.

Cartea, M.E., Francisco, M., Soengas, P., Velasco, P. 2010. Phenolic compounds in Brassica vegetables. Molecules, 16, 251-280.

De Pascale, S., Maggio, A., Pernice, R., Fogliano, V., Barbieri, G. 2007. Sulphur fertilization may improve the nutritional value of Brassica rapa L. subsp. sylvestris. European Journal of Agronomy, 26, $418-424$.

Dzotam J. K., Kuete, V. 2017. Antibacterial and Antibiotic-Modifying Activity of Methanol Extracts from Six Cameroonian Food Plants against Multidrug-Resistant Enteric Bacteria. Biomedical Research International, 2017:1583510.

El-Gaby, M. S. A., Hassan, M. I., Hussein, M. F., Ali, A.M., Elaasser, M. M., Faraghally A. F. 2018. Synthesis, characterization and in vitro biological screening of 4-hydroxy naphthalen-1-yl, naphtho[1,2-b] furan, benzo[h]chromene and 5,6dihydropyridazine derivatives containing sulfonamide moiety." Mediterranean Journal of Chemistry, 7, $346-358$.

Eltamany, E.E., Elhady, S. S., Ahmed, H. A., Badr, J. M., Noor, A. O., Ahmed, S. A., Nafie, M. S. 2020. Chemical Profiling, Antioxidant, Cytotoxic Activities and Molecular Docking Simulation of 
Eltamany et al.

Carrichtera annua DC. (Cruciferae). Antioxidants, 9, 1286.

Gulshan, A.B., Dasti, A. A., Hussain S. 2012. Indigenous uses of medicinal plants in rural areas of dera ghazi khan, punjab, pakistan. ARPN Journal of Agricultural and Biological Science, 7, 750-762.

Hanahan, D., Weinberg, R.A. 2000. The hallmarks of cancer. Cell, 100, 57-70.

Jahangir, M., Kim, H. K., Choi, Y. H., Verpoorte, R. 2009. Health-affecting compounds in Brassicaceae. Comprehensive Reviews in Food Science and Food Safety, 8, 31-43.

Kaushik, N., Agnihotri, A. 2000. GLC analysis of Indian rapeseed-mustard to study the variability of fatty acid composition. Biochemical Society Transactions, 28, 581-583.

Khan, R. U., Mehmood, S., khan, S. U., Khan, A., Shah I. A. 2013. Medicinal Value of Indigenous Flora in the Vicinity of District Bannu, Khyber Pakhtunkhwa, Pakistan. Advances in Pharmaceutical and Ethnomedicines, 1, 7-14.

Prasad. M.P. 2014. Antimicrobial potential of Brassicaceae family against clinical isolates. International journal of pure and applied bioscience, 2, 158-162.
Rec. Pharm. Biomed. Sci. 5 (2), 60-63, 2021

Prestinaci, F., Pezzotti, P., Pantosti, A. 2015. Antimicrobial resistance: a global multifaceted phenomenon. Pathogens and Global Health, 109, 309-318.

Ramirez, D., Abellán-Victorio, A., Beretta, V., Camargo, A., Moreno, D.A. 2020. Functional ingredients from Brassicaceae species: Overview and perspectives. International journal of Molecular sciences, 21, 1998.

Sasaki, K., Takahashi, T. 2002. A flavonoid from Brassica rapa flower as the UV-absorbing nectar guide. Phytochemistry, 61, 339 - 343.

Shankar, S., Segaran, G., Dhevi, R., Sundar, V., Settu, S., Sathiavelu. M. 2019. Brassicaceae: A Classical Review on Its Pharmacological Activities. International Journal of Pharmaceutical Sciences Review and Research, 55, 107-113.

Vallejo, F., Gil-Izquierdo, A., Pérez-Vicente, A., García-Viguera, C. 2004. In Vitro gastrointestinal digestion study of broccoli inflorescence phenolic compounds, glucosinolates, and vitamin C. J. Journal of Agricultural and Food Chemistry, 52, 135-138. 